\title{
Comparison of Endovascular Treatments of Ruptured Dissecting Aneurysms of the Intracranial Internal Carotid Artery and Vertebral Artery with a Review of the Literature
}

Hyoung Soo Byoun, M.D., ${ }^{1}$ Hyeong Joong Yi, M.D., Ph.D., ${ }^{2}$ Kyu Sun Choi, M.D., ${ }^{2}$ Hyoung Joon Chun, M.D., Ph.D., ${ }^{2}$ Yong Ko, M.D., Ph.D., ${ }^{2}$ Koang Hum Bak, M.D., Ph.D. ${ }^{2}$

Department of Neurosurgery, ${ }^{1}$ Seoul National University Bundang Hospital, Seongnam, Korea

Department of Neurosurgery, ${ }^{2}$ Hanyang University Medical Center, Seoul, Korea

\begin{abstract}
Objective : Subarachnoid hemorrhage (SAH) caused by rupture of an internal carotid artery (ICA) or vertebral artery (VA) dissecting aneuryesm is rare. Various treatment strategies have been used for ruptured intracranial dissections. The purpose of this study is to compare the clinical and angiographic characteristics and outcomes of endovascular treatment for ruptured dissecting aneurysms of the intracranial ICA and VA.

Methods : The authors retrospectively reviewed a series of patients with SAH caused by ruptured intracranial ICA and VA dissecting aneurysms from March 2009 to April 2014. The relevant demographic and angiographic data were collected, categorized and analyzed with respect to the outcome. Results : Fifteen patients were identified (6 ICAs and 9 VAs). The percentage of patients showing unfavorable initial clinical condition and a history of hypertension was higher in the VA group. The initial aneurysm detection rate and the percentage of fusiform aneurysms were higher in the VA group. In the ICA group, all patients were treated with double stent-assisted coiling, and showed favorable outcomes. In the VA group, 2 patients were treated with double stent-assisted coiling and 7 with endovascular trapping. Two patients died and 1 patient developed severe disability. Conclusion : Clinically, grave initial clinical condition and hypertension were more frequent in the VA group. Angiographically, bleb-like aneurysms were more frequent in the ICA group and fusiform aneurysms were more frequent in the VA group. Endovascular treatment of these aneurysms is feasible and the result is acceptable in most instances.
\end{abstract}

Key Words : Dissecting aneurysm · Endovascular treatment · Internal carotid artery · Subarachnoid hemorrhage · Vertebral artery.

\section{INTRODUCTION}

Intracranial arterial dissection may lead to significant arterial stenosis, occlusion, or pseudoaneurysm formation with subsequent hemodynamic and embolic infarcts or subarachnoid hemorrhage $(\mathrm{SAH})^{28)}$. The natural history of ruptured dissecting aneurysm is poorly defined but there is growing evidence that the risk of early rehemorrhage is comparable to that of ruptured saccular aneurysms ${ }^{1)}$. Therefore, it has been proposed that patients with SAH should undergo early obliteration of the aneurysm via either by open surgery or by endovascular procedures $^{11,18,31)}$.

Ruptured internal carotid artery (ICA) and vertebral artery (VA) dissecting aneurysms have lower mortality and morbidity rates with endovascular treatment than those reported in the literature for open surgical procedures ${ }^{6,12,21)}$. Because of the high rate of surgical morbidity, endovascular treatment has become the first line of therapy reported in most series ${ }^{1-3,27}$. To date, however, there have been no studies comparing outcomes for 2 distinct ruptured dissecting aneurysms intracranial ICA and terminal VA, treated solely by endovascular methods before the era of flow-diverting devices.

The aim of this study is to compare the clinical and angiographic characteristics, as well as the outcomes of endovascular treatment for ruptured dissecting aneurysms of the intracranial ICA and terminal VA (V4).

- Received : March 20, 2016 • Revised : May 3, 2016 •Accepted : May 16, 2016

- Address for reprints : Hyeong-Joong Yi, M.D., Ph.D.

Department of Neurosurgery, Hanyang University Medical Center, 222-1 Wangsimni-ro, Seongdong-gu, Seoul 04763, Korea

Tel : +82-2-2290-8499, Fax : +82-2-2281-0954, E-mail : hiyi8499@hanyang.ac.kr

- This is an Open Access article distributed under the terms of the Creative Commons Attribution Non-Commercial License (http://creativecommons.org/licenses/by-nc/3.0) which permits unrestricted non-commercial use, distribution, and reproduction in any medium, provided the original work is properly cited. 


\section{MATERIALS AND METHODS}

\section{Patients data}

The data were retrospectively collected from our institution. This study was approved by the Institutional Review Board in our hospital (HYIRB 2014-08-018). During a 5-year period from March 2009 to April 2014, patients who presented with SAH caused by dissecting aneurysm of the ICA and VA were selected. The selection criteria were as follows : 1) no evidence of head trauma occurring before ictus; 2) sudden onset of hemorrhagic symptoms indicating $\mathrm{SAH}$, which was confirmed on computed tomography (CT) and compatible with bleeding caused by an ICA or VA lesion; 3) cerebral angiogram demonstrating that the lesion was located in the intracranial region; and 4) cerebral angiogram showing the characteristic findings of arterial dissection.

\section{Clinical and angiographic characteristics}

Angiographic finding were classified as follows : 1) pearland-string lesion, if the dissection consisted of aneurysmal dilatations and vessel constrictions; 2) string lesion, if the dissection consisted only of a constriction; 3) fusiform aneurysm, if the dissected segment was dilated in a diffuse way; 4) bleb-like lesion, such as a small bulge on a nonbranching site without stenosis.

Clinical parameters were also analyzed. Each patient's condition on admission was evaluated according to the Hunt and Hess grade and the extent of SAH on admission CT scans was evaluated according to the Fisher classification. Hunt-Hess grade $\geq 3$ and Fisher grade $\geq 3$ were defined as less favorable initial conditions.

\section{Treatment modalities, follow-up and outcomes}

Endovascular procedures were divided into 2 categories. Double stent-assisted coiling was included in the reconstructive method, and trapping with coiling was included in the deconstructive methods. When we performed reconstructive methods with stenting, a dual-antipletelet regimen with oral acetylsalicylic acid (100 mg) and clopidogrel (75 mg) was not administered until the next day following aneurysm obliteration, and was maintained for at least 3 months, after which the clopidogrel was stopped. We did not use any antiplatelet regimen when performing deconstructive methods. The first follow-up angiography was performed at 2 weeks after the procedure, to determine whether the dissecting segment had reappeared or was wellmaintained. If a patient had neurological deterioration during this period, we performed a follow-up angiogram immediately. Regrowth and/or recanalization of aneurysms found on a follow-up angiogram were treated immediately. Sequential followup magnetic resonance angiography (MRA) was performed at 3 months, and transfemoral cerebral angiography (TFCA) at 6 months after discharge, in addition to either TFCA or MRA at 12 and 24 months after discharge. Angiographic outcomes were classified as follows : 1) complete occlusion, 2) near complete occlusion, and 3) incomplete occlusion. A modified Rankin Scale (mRS) was used to estimate neurological outcomes. Outcomes were classified as follows : 1) good recovery, an mRS score of 0 to $2 ; 2$ ) moderate disability, an $\mathrm{mRS}$ score of 3 ; 3) severe disability, an mRS score of 4 to 5 ; and 4) death.

\section{Endovascular procedures}

All patients were treated under general anesthesia. After inguinal incision, the right femoral artery was punctured. Then a 6-French shuttle catheter was placed at the level of the cervical ICA or proximal VA. We did not routinely use bolus heparin until the ruptured aneurysm was completely secured. Microcatheters and microguidewires were used for navigation and enforcement through the aneurysmal sac.

In performing the reconstructive method, we used one type of stent (Enterprise, Cordis, Miami Lakes, FL, USA). The stent was deployed across the aneurysm neck after placement of a microcatheter in the aneurysm sac. We made a frame with the first coil with/without jailing technique. Then, coil packing was performed as much as possible. When another stent deployment was needed, the "stent within a stent technique" was used. Trapping with coiling was performed with double microcatheter technique. After 2 microcatheters were navigated to the justdistal portion of the dissecting aneurysm, a frame was made using 2 frame coils. One frame coil was detached and the wire was removed. Another frame coil was left undetached. Coil packing was performed through only 1 microcatheter. If the coil mass was stable, another frame coil was detached. Then coil packing was continued until the parent artery was completely trapped.

After the final angiography, the microcatheter and shuttle catheter were removed. The puncture site was closed with a closure device, and we checked whether the dorsalis pedis pulsation was intact. Patients treated with the reconstructive method were moved to the neurosurgical intensive care unit for monitoring and received heparin to maintain an activated clotting time (aCT) of around 200 seconds until midnight.

\section{RESULTS}

During the study period, 501 patients with intracranial artery aneurysms were treated in our institution (295 ruptured and 206 unruptured aneurysms). Thirty-five patients had dissecting aneurysms. Of these, we identified 24 consecutive patients with dissecting aneurysms who presented with SAH. Nine patients who were treated with open microsurgery were excluded from our study, leaving a total of 15 patients enrolled (6 ICAs and 9 VAs). Clinical characteristics and treatment options, angiographic outcomes, and clinical outcomes are summarized in Table 1, 2.

\section{In ICA group $(\mathbf{n}=6)$}

The mean age was 45.6 and the male : female ratio was $3: 3$. No patients had hypertension. Three patients showed a Fisher grade $<3$, and 5 patients showed a Hunt and Hess grade $<3$. There were 5 angiographic bleb-like lesions and 1 fusiform lesion. All the dissections were treated with stent-assisted coiling. 
Table 1. Summary of clinical presentations and treatment outcomes in 6 patients with subarachnoid hemorrhage caused by the intracranial internal carotid artery dissections

\begin{tabular}{|c|c|c|c|c|c|c|c|c|c|c|c|}
\hline Case No. & Sex/age & $\begin{array}{l}\text { HH-scale } \\
\text { F-grade }\end{array}$ & HTN & $\begin{array}{l}\text { Angiographic } \\
\text { finding }\end{array}$ & $\begin{array}{c}\text { Side of } \\
\text { dissection }\end{array}$ & $\begin{array}{l}\text { Rebleeding } \\
\text { regrowth }\end{array}$ & $\begin{array}{l}\text { Primary } \\
\text { treatment }\end{array}$ & $\begin{array}{c}\text { Secondary } \\
\text { treatment }\end{array}$ & $\begin{array}{c}\text { Immediate } \\
\mathrm{AO}\end{array}$ & $\begin{array}{l}\mathrm{F} / \mathrm{U} \\
\mathrm{AO}^{\ddagger}\end{array}$ & $\mathrm{mRS}$ \\
\hline 1 & $\mathrm{M} / 43$ & $2 / 2$ & $(-)$ & Fusiform & Left & $(-/-)$ & DSAC & None & ICO & $\mathrm{CO}$ & 0 \\
\hline 2 & $\mathrm{~F} / 45$ & $2 / 2$ & $(-)$ & Bleb-like & Right & $(-/+)$ & DSP & Coil packing & $\mathrm{NCO}$ & $\mathrm{CO}$ & 0 \\
\hline 3 & $\mathrm{~F} / 54$ & $3 / 4$ & $(-)$ & Bleb-like & Right & $(-/+)$ & SAC & SAC & $\mathrm{NCO}$ & $\mathrm{CO}$ & 1 \\
\hline 4 & $\mathrm{M} / 41$ & $2 / 3$ & $(-)$ & Bleb-like & Right & $(-/-)$ & DSAC & None & ICO & $\mathrm{CO}$ & 0 \\
\hline 5 & $\mathrm{M} / 39$ & $2 / 2$ & $(-)$ & Bleb-like & Right & $(-/-)$ & DSAC & None & ICO & $\mathrm{CO}$ & 0 \\
\hline 6 & $\mathrm{~F} / 52$ & $2 / 3$ & $(-)$ & Bleb-like & Left & $(-/-)$ & DSAC & None & ICO & ICO & 1 \\
\hline
\end{tabular}

${ }^{*}$ Primary treatment was performed immediately as soon as the aneurysm was detected, ${ }^{\dagger}$ Secondary treatment was performed when an aneurysms were recurred on follow-up angiography at 2 weeks, ${ }^{\ddagger}$ Follow-up angiography was performed at 6 months after discharge. AO : angiographic outcome, CO : complete occlusion, DSAC : double stent-assisted coiling, DSP : double stent placement, F-grade : Fisher-grade, HH-scale : Hunt and Hess grade, HTN : hypertension, ICO : incomplete occlusion, mRS : modified Rankin Scale, NCO : near complete occlusion, SAC : single stent-assisted coiling

Table 2. Summary of clinical presentations and treatment outcomes in 9 patients with subarachnoid hemorrhage caused by the intracranial vertebral artery dissections

\begin{tabular}{|c|c|c|c|c|c|c|c|c|c|c|c|c|}
\hline $\begin{array}{l}\text { Case } \\
\text { No. }\end{array}$ & $\begin{array}{l}\text { Sex/ } \\
\text { age }\end{array}$ & $\begin{array}{l}\text { HH-grade } \\
\text { F-grade }\end{array}$ & HTN & $\begin{array}{l}\text { Angiographic } \\
\text { finding }\end{array}$ & $\begin{array}{c}\text { VA } \\
\text { dominance }\end{array}$ & $\begin{array}{c}\text { Side of } \\
\text { dissection }\end{array}$ & $\begin{array}{c}\text { Site of } \\
\text { dissection }\end{array}$ & $\begin{array}{l}\text { Rebleeding } \\
\text { regrowth }\end{array}$ & Treatment & $\mathrm{mRS}$ & $\begin{array}{c}\text { Immediate } \\
\mathrm{AO}\end{array}$ & $\begin{array}{l}\mathrm{F} / \mathrm{U} \\
\mathrm{AO}^{*}\end{array}$ \\
\hline 7 & $\mathrm{M} / 52$ & $1 / 4$ & $(+)$ & Fusiform & Right & Right & Across PICA & $(+/-)$ & DSAC & 6 & ICO & $(-)$ \\
\hline 8 & $\mathrm{M} / 75$ & $1 / 3$ & $(+)$ & Fusiform & Right & Right & Distal to PICA & $(-/-)$ & DSAC & 0 & $\mathrm{NCO}$ & $\mathrm{CO}$ \\
\hline 9 & $\mathrm{M} / 32$ & $4 / 4$ & $(+)$ & $P \& S$ & Codominance & Left & Prox. To PICA & $(-/-)$ & TWC & 1 & $\mathrm{CO}$ & $\mathrm{CO}$ \\
\hline 10 & $\mathrm{M} / 56$ & $5 / 4$ & $(+)$ & Fusiform & Codominance & Left & Distal to PICA & $(-/-)$ & TWC & 6 & $\mathrm{CO}$ & $(-)$ \\
\hline 11 & $\mathrm{~F} / 49$ & $4 / 4$ & $(-)$ & Fusiform & Codominance & Right & PICA not visible ${ }^{\dagger}$ & $(-/-)$ & TWC & 1 & $\mathrm{CO}$ & $\mathrm{CO}$ \\
\hline 12 & $\mathrm{M} / 52$ & $3 / 4$ & $(-)$ & $\mathrm{P} \& \mathrm{~S}$ & Left & Right & Across PICA $^{\ddagger}$ & $(-/-)$ & TWC & 0 & $\mathrm{CO}$ & $\mathrm{CO}$ \\
\hline 13 & $\mathrm{M} / 39$ & $4 / 4$ & $(-)$ & Fusiform & Left & Right & Distal to PICA & $(-/-)$ & TWC & 1 & $\mathrm{CO}$ & $\mathrm{CO}$ \\
\hline 14 & $\mathrm{M} / 68$ & $3 / 4$ & $(+)$ & Fusiform & Codominance & Right & Prox. to PICA & $(-/-)$ & TWC & 4 & $\mathrm{CO}$ & $\mathrm{CO}$ \\
\hline 15 & $\mathrm{~F} / 44$ & $3 / 4$ & $(-)$ & Fusiform & Codominance & Left & Prox. to PICA & $(-/-)$ & TWC & 1 & $\mathrm{CO}$ & $\mathrm{CO}$ \\
\hline
\end{tabular}

${ }^{*}$ Follow-up angiography was performed at 6 months after discharge, ${ }^{\dagger}$ Right PICA was not visible, but right AICA perfused right Inferior cerebellar territory, ${ }^{\ddagger}$ Right AICA, left PICA perfused right inferior cerebellar territory. AICA : anterior inferior cerebellar artery, AO : angiographic outcome, CO : complete occlusion, DSAC : double stentassisted coiling, F-grade : Fisher-grade, F/U : follow-up, HH-scale : Hunt and Hess grade, ICO : incomplete occlusion, mRS : modified Rankin Scale, NCO : near complete occlusion, P \& S : pearl \& string, PICA : posterior inferior cerebellar artery, Prox. : proximal, TWC : trapping with coiling, VA : vertebral artery

Six patients were treated with double stent-assisted coiling. Staged intervention was performed on 2 patients. One patient (Case 2) was treated by double stent placement alone initially, because the aneurysm was too small to insert even a single coil, and a tiny bleb was seen on the dome of the aneurysm. Regrowth of the aneurysm was found on follow-up angiography at 2 weeks after stent placement. Additional coiling was performed. Another patient (Case 3) was initially treated with single stent-assisted coiling. However, regrowth of the aneurysm was found on follow-up angiography at 2 weeks after coiling. Additional stentassisted coiling was performed accordingly. There was 1 intraoperative aneurysmal rupture during the secondary intervention (Case 2), but coil packing was performed immediately without any incident. Immediate angiography showed near-complete (2 patients), or incomplete (4 patients) outcomes. Follow-up angiography showed 5 complete and 1 incomplete (but stable) outcomes at 6 months. There was no perioperative rebleeding, and all patients showed favorable outcomes (4 with an mRS score of 0, 2 with a score of 1). Typical cases are illustrated in Fig. 1,2.

\section{In VA group $(\mathrm{n}=9)$}

The mean age was 51.9 and the male : female ratio was $7: 2$.
Five patients had hypertension on oral antihypertensive medications. All patients had a Fisher grade $\geq 3$, and 7 patients had a Hunt and Hess grade $\geq 3$. There were 2 angiographic pearl-andstring lesions and 7 fusiform lesions. If important branch vessels were not incorporated in the segment of the vessel to be occluded, and collateral blood flow to the remainder of the posterior circulation was adequate, we used trapping with coiling. However if the affected vessel was dominant and the major branch vessels were incorporated in the dissecting segment, double stentassisted coiling was used. Two dissections were treated with double stent-assisted coiling and 7 other patients were treated with trapping with coiling the same day as ictus. Immediate angiographic outcomes were complete (7 patients), near-complete (1 patient), or incomplete (1 patient). Follow-up angiographic outcomes of 7 patients were all complete at 6 months. Six patients had favorable neurological outcomes. One patient had severe disability and 2 died due to postoperative rebleeding and severe brain edema, respectively. Typical cases are illustrated in Fig. 3, 4.

\section{DISCUSSION}

Dissecting intracranial aneurysm as the source of SAH is rel- 

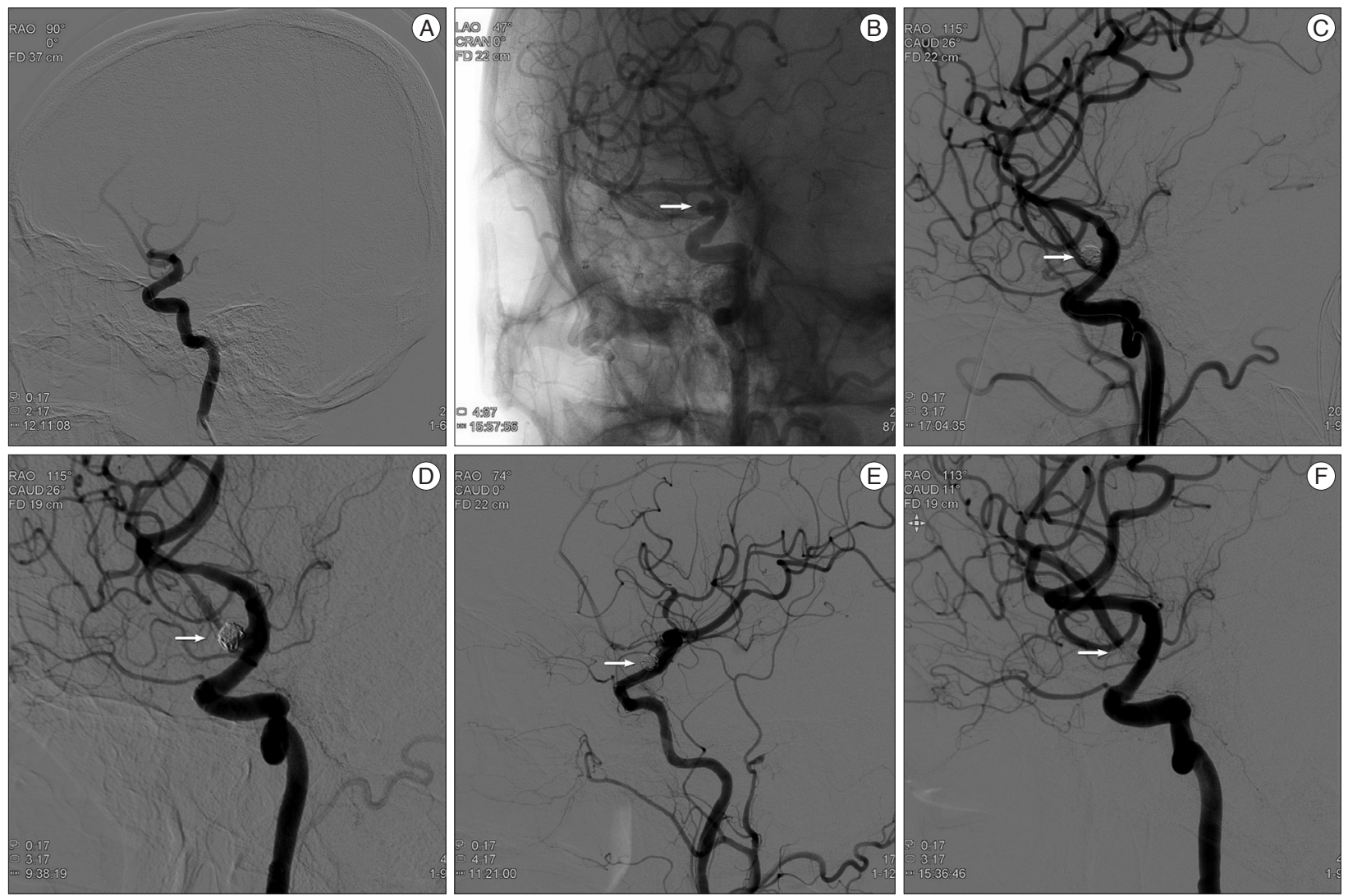

Fig. 1. ICA Case 3. A 54-year-old woman, Hunt and Hess grade 3, presented with Fisher grade 4 SAH. A : Femoral angiogram demonstrates suspicious outpouching on the right supraclinoid carotid artery. B : Angiogram after 7 days revealed saccular outgrowth indicating dissecting aneurysm (white arrow). C : Stent-assisted coiling was performed (Enterprise 4.5/28 mm) with resultant near complete occlusion without contrast leakage (white arrow). D : Follow-up angiography after 2 weeks revealed regrowth of aneurysmal sac. Additional stent-assisted coiling (Enterprise 4.5/28) was performed (white arrow). E : Final angiogram showed near complete occlusion of the aneurysm (white arrow). F : After 6 months, follow-up angiogram showed no evidence of aneurysmal regrowth (white arrow). ICA : internal carotid artery, SAH : subarachnoid hemorrhage.

atively rare and knowledge with regard to the etiology, natural history and treatment options is limited. Reports of dissecting intracranial ICA and VA aneurysms as a cause of SAH are rare ${ }^{17,211}$. The findings of Uhl et al. ${ }^{28)}$ are consistent with other reports of an extremely negative prognosis of unsecured ruptured intracranial dissecting aneurysms ${ }^{18,20}$. In our series, we tried to manage patients as soon as the dissecting aneurysm was found. If the dissection was not definite on initial angiography in patients with diffuse SAH, we performed follow-up angiography. Fortunately, there was no preoperative rebleeding before we found the causative dissecting aneurysm.

\section{Comparison of ruptured VA and ICA dissecting aneurysms}

Comparisons of ICA and VA groups are summarized in Table 3. The proportion of males was higher than females in the VA group. A history of hypertension and clinical presentation of SAH was different between the 2 groups. The percentage of patients with a more severe initial clinical condition (Hunt and Hess grade $\geq 3$ ) and history of hypertension were higher in the VA group. Fusiform aneurysms were more frequently seen in the VA group (77.8\%) than the ICA group (16.7\%). The initial detection rate was higher in the VA group (100\%) than the ICA group (33.3\%).

Outcomes on immediate angiography included 7 complete occlusions (77.8\%) in the VA group but we could not achieve complete occlusion in the ICA group. There was 1 case of rebleeding in the VA group during the first follow-up period. There were 5 complete occlusions in the ICA group, but no regrowth of the aneurysm or recanalization in both groups on final angiography after 6 months. Six patients had good neurologic outcomes (mRS 0-1) in each group (6/6 in the ICA group vs. 6/9 in the VA group). Morbidity and mortality rates were higher in the VA group.

Yonekawa et al. ${ }^{32)}$ reported that clinical presentation of SAH was usually more severe in cases of ICA dissection than in VA dissection, but did not reach statistical significance. In the current study, the clinical presentation of SAH was different from previous studies, and was usually more severe in cases of the VA dissection than in ICA dissection. However, we could not show statistical results due to small number of cases.

The most characteristic clinical feature of this disease is its susceptibility to rebleeding. Dissecting aneurysms of the VA and ICA are vulnerable. Ohkuma et al. ${ }^{21}$ reported that pathological examination of the aneurysm bulge obtained during sur- 

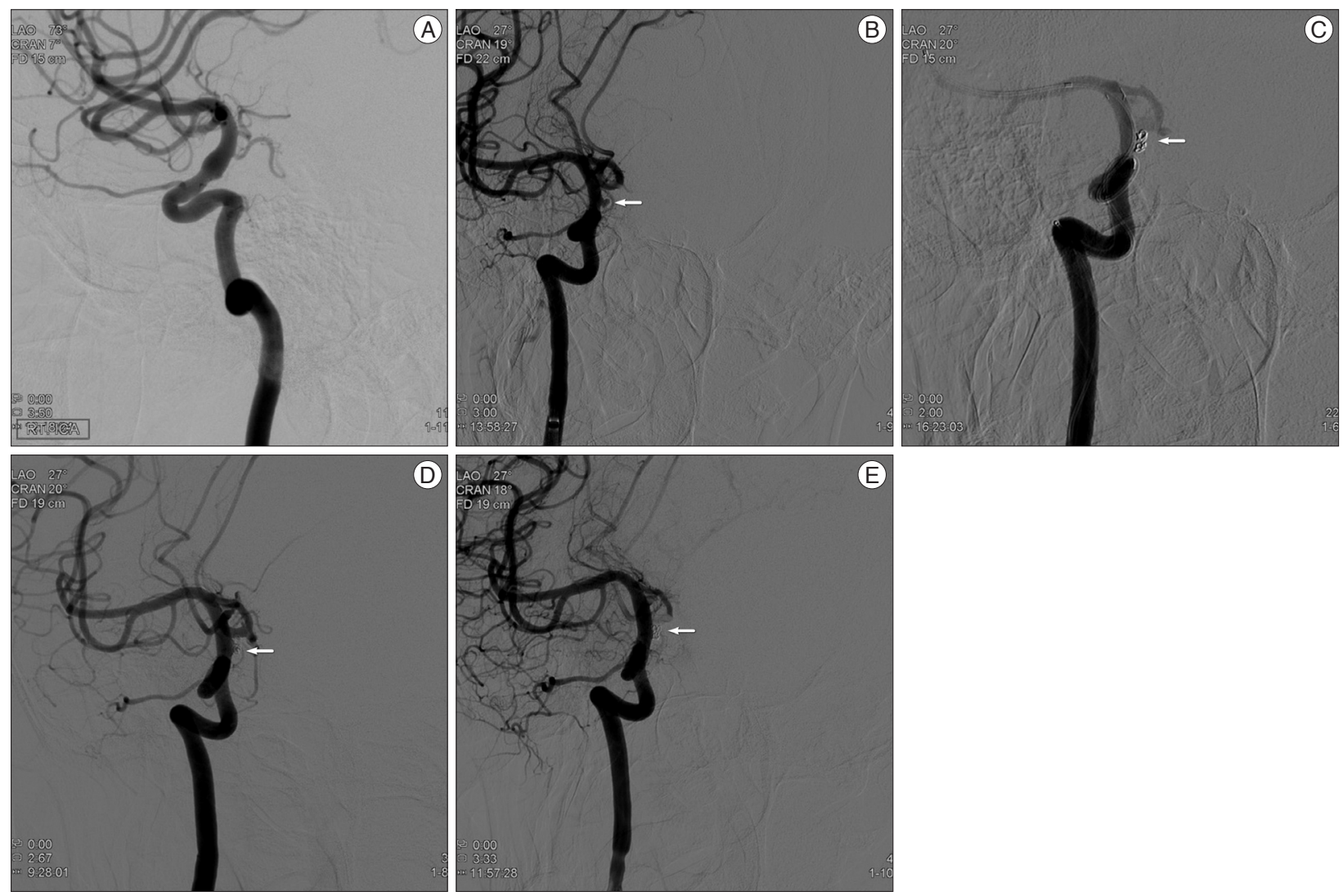

Fig. 2. ICA Case 5. A 39-year-old man, Hunt and Hess grade 2, was presented with Fisher grade 2 SAH. A : Angiogram revealed unremarkable results similar to CT angiogram. He was admitted to the intensive care unit for close observation. B : On the 5th hospital day, angiogram revealed a bleb-like dissecting aneurysm (white arrow) on the right distal carotid artery. C : Double stent-assisted coiling was performed (Enterprise 4.5/22, 4.5/28 mm), and control angiogram showed incomplete occlusion of the dissecting aneurysm (white arrow). D : Follow-up angiogram after 2 weeks failed to show any change in the lesion (white arrow). E : Follow-up angiogram after 6 months revealed further thrombosis within the aneurysm (white arrow). ICA : internal carotid artery, SAH : subarachnoid hemorrhage.

gery revealed that the wall only consisted of thin adventitia and fibrinous tissue with disruption of the intima and media. This wall structure may contribute both to the rapid enlargement of the aneurysm bulge on angiography and to the ease of laceration by manipulation during surgery. They demonstrated that the prehospitalization rebleeding rate of dissecting aneurysms was higher than those of saccular aneurysms. This high rate of rebleeding before admission partially contributed to the higher Hunt and Hess grades $(\geq 3)$ on admission ${ }^{21)}$. In the present study, 7 patients $(78.8 \%)$ with VA dissection had high Hunt and Hess grade ( $\geq 3$ ) but just 1 patient (16.7\%) with ICA dissection showed a high Hunt and Hess grade. Rebleeding might occur more often in the VA group, and these results indicate that VA dissecting aneurysms might be more susceptible to bleeding than ICA dissecting aneurysms. Sakata et al. ${ }^{23)}$ reported that hypertension might function as a causal factor in the pathogenesis of intracranial dissecting aneurysms and trigger formation of a dilated pseudoaneurysm with widespread disruption of the entire arterial wall. In our results, hypertension contributed to more frequent formation of fusiform aneurysms in patients with a VA dissecting aneurysm.

Our results differed from previous report ${ }^{24)}$. Patients with rup- tured ICA dissecting aneurysms had strikingly favorable outcomes. Despite early and proper treatment, 2 patients with VA dissecting aneurysms died and 1 patient had a poor outcome. These results imply that the larger volume of distribution of the $\mathrm{SAH}$ in the prepontine and premedullary area might lead to more severe damage to the brainstem in the VA group. As a result, the patients with ruptured VA dissecting aneurysms had poorer outcomes than patients with ICA dissecting aneurysms did.

\section{Endovascular treatment of dissecting aneurysms}

Since the late 1990s, endovascular treatment of dissecting aneurysms has become the first line of treatment reported in most series in the form of proximal parent artery occlusion, endovascular trapping, and/or intracranial stenting due to the high rate of surgical morbidity ${ }^{4,7,30)}$.

The endovascular approach to dissection of the intracranial artery can be divided into either reconstructive (preserving blood flow through the parent vessel) or deconstructive (involving occlusion or sacrifice of the parent artery) procedures ${ }^{19)}$. Reconstructive endovascular techniques consist of stent placement, including stent implantation and stent-assisted coil embolization. These techniques preserve the parent vessel, which elimi- 

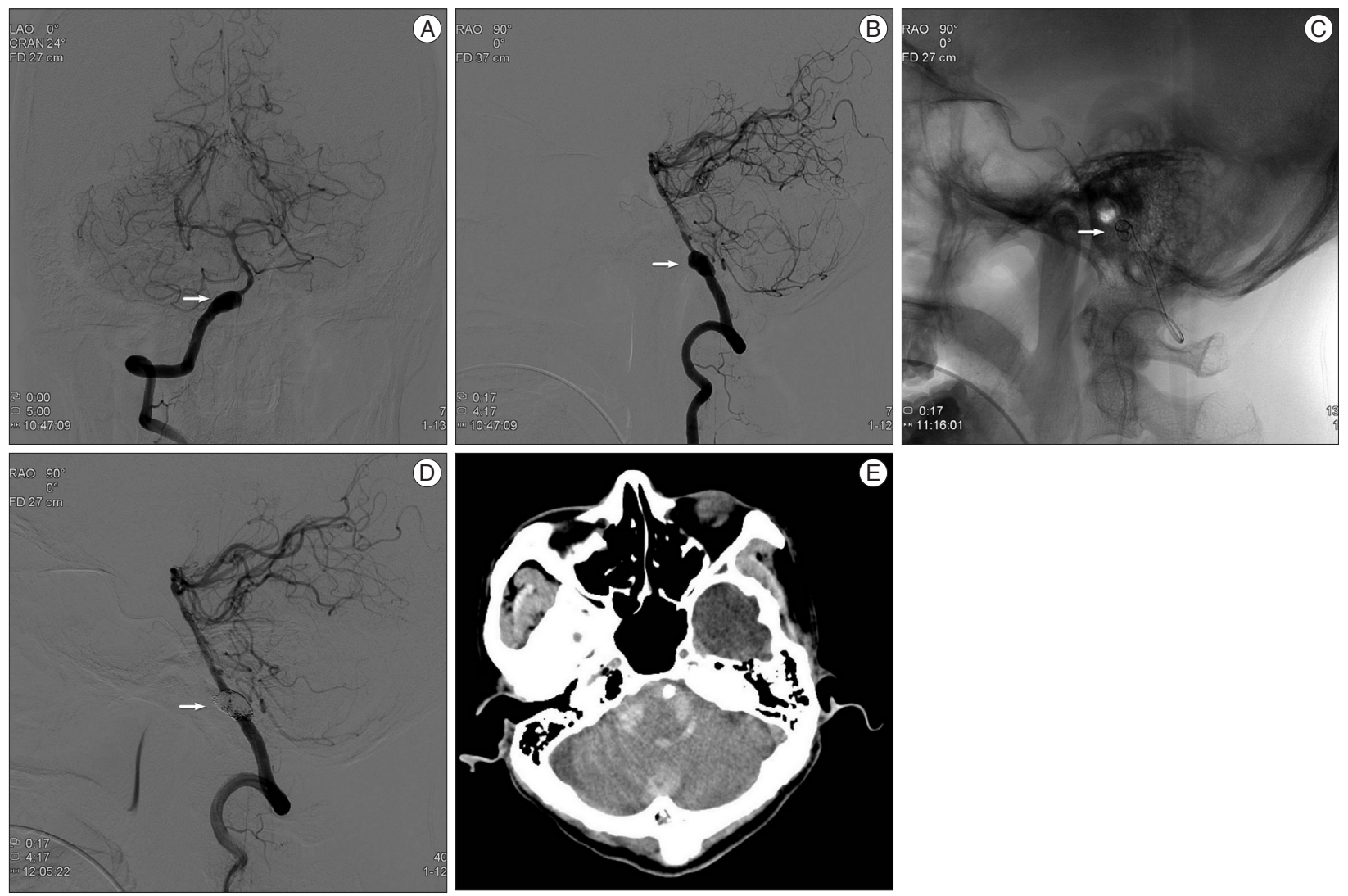

Fig. 3. VA Case 7. A 52-year-old man, Hunt and Hess grade 1, was presented with Fisher grade 4 SAH. A and B : Angiogram demonstrated a definite dissecting aneurysm (white arrow) on the right VA traversing the right posterior inferior cerebellar artery (PICA). Right VA was the dominant vessel, and the dissecting aneurysm incorporated the origin of the right PICA. C : Double stent insertion was performed (Enterprise, 4.5/28, 4.5/37 mm), and then, 14 coils were then placed in the aneurysmal sac with jailing technique (white arrow). D : Final angiogram showed partial occlusion of the aneurysm, but without any contrast leakage. He improved gradually until the 14th hospital day (white arrow). E : Brain CT showed dense infratentorial SAH and intraventricular hemorrhage in the 4th ventricle. He remained unconsciousless for a few days until demise. VA : vertebral artery, SAH : subarachnoid hemorrhage.

nates the need for revascularization when angiography demonstrates inadequate collateral flow, or when the dissected segment involves major branch vessels. Deconstructive endovascular techniques include proximal parent artery occlusion (PAO) with detachable coils and/or balloons and occlusion of the dissected segment of the vessel with coils and/or balloons ${ }^{2,10}$.

A recent series reported various endovascular treatment modalities for dissecting aneurysms. Lee et al. ${ }^{14)}$ treated blister-like aneurysms (BBAs) of the ICA with reconstructive endovascular methods. All 9 BBAs were initially treated with single stent-assisted coil (SAC) embolization. This was followed by a second stent insertion using the stent-within-a-stent (SWS) technique in 3, covered stent placement in 3, and SAC embolization alone in 3. They demonstrated that the SWS and covered-stent techniques can be considered as an alternative treatment option for BBAs in selected patients in whom ICA sacrifice is not feasible. Moreover, stent-assisted coiling alone seems insufficient to prevent BBA regrowth ${ }^{14)}$. Ahn et al. ${ }^{1)}$ treated dissecting aneurysms of the VA with the double stent technique. They suggested that double stent placement offered a viable alternative to complex surgical procedures or destructive procedures. Mohammadian et al. ${ }^{19)}$ treated 10 patients who had ruptured dissecting aneurysms of the VA and 4 patients who had ruptured dissecting aneurysm of the ICA with endovascular procedures. They suggested that favorable outcomes can be achieved following PAO with coil embolization as an endovascular approach for ruptured ICA and VA dissecting aneurysms. Recent series of endovascular treatments of ruptured ICA and VA dissecting aneurysms are summarized in Table 4.

Recently, flow diverters have been used for endovascular treatment of dissecting aneurysms. Fisher et al. ${ }^{5}$ reported their initial experience and longterm follow-up of pipeline embolization devices for treatment of fusiform and dissecting aneurysms. In their study, the cure rate of the lesions was $58 \%$, and morbidity and mortality in the entire seires were $5 \%$ and $7 \%$, respectively. van Oel et al. ${ }^{29)}$ treated fusiform and dissecting aneurysms of the basilar trunk with reconstructive endovascular methods using flow diverters, stents and coils. They treated 2 patients using additional flow diverters, but the outcomes of these patients were poor. Unfortunately, because flow diverters are not approved for use in ruptured intracranial dissecting aneurysms in Korea, we have no experience with this application. 

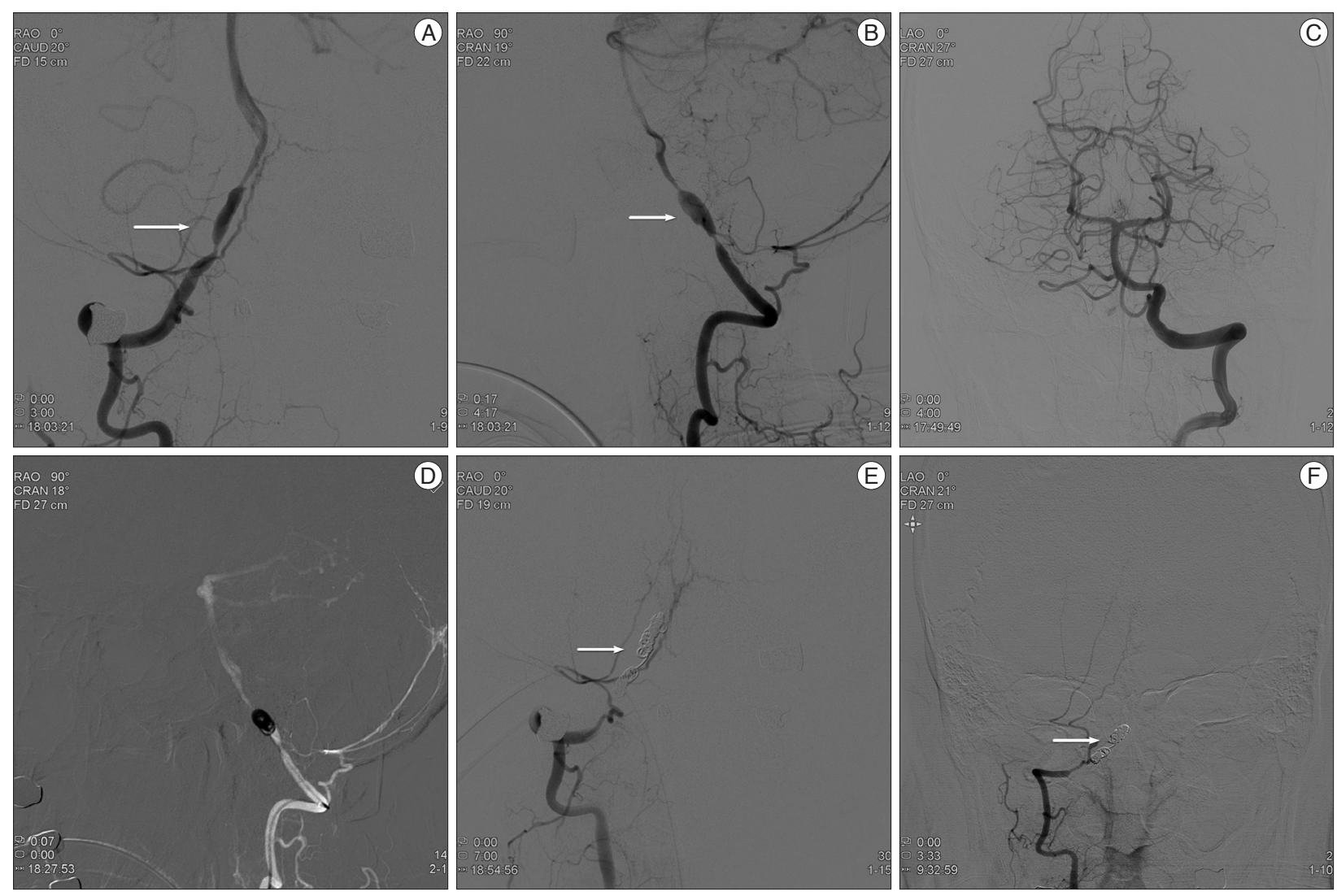

Fig. 4. VA Case 12. A 52-year-old man, Hunt and Hess grade 3, was presented with Fisher grade 4 SAH. A and B : Angiogram demonstrated a typical pearl and string dissection (white arrow) in the right VA incorporating the right PICA. C : Left VA was the dominant vessel, and the dissecting aneurysm in the right VA incorporated the origin of the right PICA. However, the inferior territory of the cerebellum was perfused by the right anterior inferior cerebellar artery and the left PICA. D : Right VA was sacrificed with trapping with coiling. E : Final angiogram showed complete occlusion of the aneurysm and inferior cerebellar perfusion was intact (white arrow). $\mathrm{F}$ : After 6 months, follow-up angiogram showed no evidence of recanalization or aneurysmal regrowth (white arrow). VA : vertebral artery, SAH : subarachnoid hemorrhage, PICA : posterior inferior cerebellar artery.

Table 3. Comparison of ruptured ICA and VA dissecting aneurysms

\begin{tabular}{lcc}
\hline \multicolumn{1}{c}{ Variables } & ICA $(\mathrm{n}=6)[\mathrm{n}(\%)]$ & VA $(\mathrm{n}=9)[\mathrm{n}(\%)]$ \\
\hline Age (yrs) & $39-54($ mean : 45.6) & $32-75($ mean : 51.9) \\
Sex (male : female) & $3: 3$ & $7: 2$ \\
Hunt-Hess grade $(\geq 3)$ & $1(16.7)$ & $7(77.8)$ \\
Fisher grade $(\geq 3)$ & $3(50)$ & $9(100)$ \\
History of hypertension & $0(0)$ & $5(55.6)$ \\
Aneurysm type (fusiform) & $1(16.7)$ & $7(77.8)$ \\
Initial aneurysm detection & $2(33.3)$ & $9(100)$ \\
Rebleeding rate & $0(0)$ & $1(11.1)$ \\
Regrowth of aneurysm & $0(0)$ & $0(0)$ \\
Immediate AO (CO) & $0(0)$ & $7(77.8)$ \\
Final AO (CO)* & $5(83.3)$ & $7(100)^{\dagger}$ \\
Neurologic outcome & & $6(66.7)$ \\
$\quad$ Good recovery & $6(100)$ & $1(11.1)$ \\
$\quad$ Not good recovery & & $2(22.2)$ \\
$\quad$ Severe disability & $0(0)$ & $0(0)$ \\
$\quad$ Death (mortality rate) & &
\end{tabular}

${ }^{*}$ Final angiographic outcome was estimated at 6months after discharge, ${ }^{\dagger}$ Two patients expired before final angiography. AO : angiographic outcome, $\mathrm{CO}$ : complete occlusion
In our study, we managed ICA dissecting aneurysms with double stent-assisted coiling. No patients had perioperative complications or unfavorable outcomes. Patients who were not treated with double stent-assisted coiling required secondary endovascular treatment. We also treated the VA dissecting aneurysms with double stent-assisted coiling (2 patients), and trapping with coiling (7 patients). One patient who was incompletely treated with double stent-assisted coiling suffered postoperative rebleeding. In contrast, all patients who were treated with trapping with coiling experienced no postoperative rebleeding or aneurysmal regrowth. In our experiences, reconstructive methods with double stent-assisted coiling seem to be feasible for treatment of ICA dissecting aneurysms, and the deconstructive methods with trapping with coiling seem to be more for treatment of VA dissecting aneurysms.

\section{Limitations of the study}

There were several limitations. This study was retrospective and consisted of only the available data at a single institution. The sample size is too small. Moreover, we treated our patients with a variety of endovascular techniques. However, because of the lack of a standardized guidelines and long-term experience 
Table 4. Review of endovascular treatment of ruptured ICA and VA dissecting aneurysms

\begin{tabular}{|c|c|c|c|c|}
\hline Study, authors (year) & H-H/Fisher $(\geq 3)(\mathrm{N})$ & Treatment (n) & Complication (n) & Outcome (n) \\
\hline \multicolumn{5}{|l|}{ ICA group } \\
\hline \multirow[t]{2}{*}{ Meling et al. $(2008)^{16)}$} & $2 / 2(3)$ & Trapping (1) & Infarction (1) & GOS $1(1), 5(2)$ \\
\hline & & Coiling (2) & No & \\
\hline \multirow[t]{3}{*}{ Lee et al. $(2009)^{14)}$} & 7/NA (9) & SAC (3) & Regrowth (3) & GOS $5(5)$ \\
\hline & & SAC+SWS (3) & No & \\
\hline & & $\mathrm{SAC}+\mathrm{CS}(3)$ & ICA rupture (1) & $\mathrm{D}(1)$ \\
\hline \multirow[t]{3}{*}{ Meckel et al. $(2011)^{15)}$} & 3/6 (11) & $\operatorname{SAC}(9)$ & Rebleeding (1), regrowth (2) & mRS 0 (7), $2(1), 6(1)$ \\
\hline & & $\mathrm{PAO}(1)$ & No & \\
\hline & & DS (1) & Rebleeding and regrowth (1) & $2(1), 0(1)$ \\
\hline \multirow[t]{4}{*}{ Gonzalez et al. $(2013)^{6}$} & NA/9 (10) & SAC (3) & Embolic (1), rebleeding (1) & mRS 1 (1), $2(2)$ \\
\hline & & SS (1) & No & $1(1)$ \\
\hline & & MS (5) & Intra-stent clot (1) & $1(2), 2(2), 3(1)$ \\
\hline & & Trapping (1) & Embolic and rebleeding (1) & $2(1)$ \\
\hline Mohammadian et al. $(2013)^{19)}$ & 3/NA (4) & $\mathrm{PAO}(4)$ & No & mRS 0 (2), 1 (2) \\
\hline \multirow[t]{2}{*}{ Kim et al. $(2014)^{9)}$} & $5 / 4(11)$ & Trapping, primary (7) & Infarction (1) & mRS 0 (5), 1 (1), 6 (1) \\
\hline & & Secondary (4) & & $0(2), 4(1), 5(1)$ \\
\hline \multirow[t]{3}{*}{ Present series } & $1 / 3(6)$ & SAC+SAC (1) & Regrowth (1) & mRS 1 (1) \\
\hline & & DS+coiling (1) & Regrowth (1) & $0(1)$ \\
\hline & & $\operatorname{DSAC}(4)$ & No & $0(3), 1(1)$ \\
\hline \multicolumn{5}{|l|}{ VA group } \\
\hline Kurata et al. $(2001)^{13)}$ & 11/NA (18) & Coiling & No & $\begin{array}{l}\text { GR (12), MD (2), VS (1), } \\
\text { dead (3) }\end{array}$ \\
\hline \multirow[t]{3}{*}{ Rabinov et al. $(2003)^{22)}$} & 14/NA (18) & $\mathrm{PAO}(8)$ & Rebleeding (2) & mRS 0 (1), $2(1), 5(3)$ \\
\hline & & & & Unknown (3) \\
\hline & & Trapping (10) & Regrowth (2) & $0(4), 1,2,3,4(1), 5(2)$ \\
\hline Ahn et al. $(2005)^{1)}$ & NA & DS (3) & & $0(2), 1(1)$ \\
\hline \multirow[t]{2}{*}{ Sugiu et al. $(2005)^{25)}$} & 18/NA (20) & SAC (1), coiling (1) & Rebleeding (1) & $\operatorname{SD}(1), \mathrm{GR}(1)$ \\
\hline & & VA occlusion (18) & & GR (11), MD (3), D (4) \\
\hline Ahn et al. $(2006)^{2)}$ & NA & SAC (1), DS (1) & No & mRS $1(1), 2(1)$ \\
\hline \multirow[t]{2}{*}{ Taha et al. $(2010)^{26)}$} & NA & Trapping (NA) & Rebleeding (1) & GR (8), MD (5), VS (1) \\
\hline & & +SAC (NA) (17) & Ischemic (2) & $\mathrm{D}(3)$ \\
\hline \multirow[t]{2}{*}{ Kashiwazaki et al. $(2013)^{8)}$} & 26/NA (45) & Trapping (45) & Permanent (3) & mRS 0 (34), 1, 2, 5 (1), 6 (8) \\
\hline & & & Temporary (6) & \\
\hline Mohammadian et al. $(2013)^{19)}$ & 9/NA (10) & $\mathrm{PAO}(10)$ & Emboic (3) & mRS 0 (7), 2 (2), 6 (1) \\
\hline \multirow[t]{2}{*}{ Present series } & $7 / 9(9)$ & $\operatorname{DSAC}(2)$ & Rebleeding (1) & mRS 0 (1), $6(1)$ \\
\hline & & Trapping (7) & No & $0(1), 1(4), 4(1), 6(1)$ \\
\hline
\end{tabular}

CS : covered stent, D : death, DS : double stenting, DSAC : double stent-assisted coiling, GOS : Glasgow Outcome Scale, GR : good recovery, H-H/Fisher : Hunt-Hess grade/Fisher grade, MD : moderate disability, mRS : modified Rankin Scale, MS : multiple stenting, $\mathrm{N}$ : total cases, $\mathrm{n}:$ number of cases, NA : not available; PAO : parent artery occlusion, SAC : single stent-assisted coiling, SS : single stenting, SWS : stent within a stent, VS : vegetative state

with endovascular treatment of ruptured dissecting aneurysms, our experience at least would support the evaluation of treatment strategies for ruptured dissecting aneurysms.

Despite these limitations, this is the first study to compare the clinical and angiographic characteristics as well as the outcomes of endovascular treatment of ruptured ICA and VA dissecting aneurysms. This study also provides greater understanding of the difference between ruptured ICA and VA dissecting aneurysms, and may help surgeons choose among treatment modalities.

\section{CONCLUSION}

The reported experience suggests that there are clinical and angiographic differences between ruptured intracranial ICA and VA dissecting aneurysms. Clinically, grave initial clinical condition and hypertension were more frequent in the patients with ruptured intracranial VA dissecting aneurysms. Angiographically, bleb-like aneurysms were more frequent in the ICA group and fusiform aneurysms were more frequent in the VA group.

Endovascular treatment of these aneurysms seems feasible and the result is acceptable. The long-term efficacy and durabil- 
ity of endovascular treatment for dissecting aneurysms remains to be determined in a larger prospective series.

\section{References}

1. Ahn JY, Chung SS, Lee BH, Kim SH, Yoon PH, Joo JY, et al. : Treatment of spontaneous arterial dissections with stent placement for preservation of the parent artery. Acta Neurochir (Wien) $147: 265-273$; discussion 273, 2005

2. Ahn JY, Han IB, Kim TG, Yoon PH, Lee YJ, Lee BH, et al. : Endovascular treatment of intracranial vertebral artery dissections with stent placement or stent-assisted coiling. AJNR Am J Neuroradiol 27 : 1514-1520

3. Albuquerque FC, Fiorella DJ, Han PP, Deshmukh VR, Kim LJ, McDougall CG : Endovascular management of intracranial vertebral artery dissecting aneurysms. Neurosurg Focus 18 : E3, 2005

4. Anxionnat R, de Melo Neto JF, Bracard S, Lacour JC, Pinelli C, Civit T, et al. : Treatment of hemorrhagic intracranial dissections. Neurosurgery 53 : 289-300; discussion 300-301, 2003

5. Fischer S, Perez MA, Kurre W, Albes G, Bäzner H, Henkes H : Pipeline embolization device for the treatment of intra- and extracranial fusiform and dissecting aneurysms : initial experience and long-term follow-up. Neurosurgery 75 : 364-374; discussion 374, 2014

6. Gonzalez AM, Narata AP, Yilmaz H, Bijlenga P, Radovanovic I, Schaller $\mathrm{K}$, et al. : Blood blister-like aneurysms : single center experience and systematic literature review. Eur J Radiol 83 : 197-205, 2014

7. Hamada J, Kai Y, Morioka M, Yano S, Todaka T, Ushio Y : Multimodal treatment of ruptured dissecting aneurysms of the vertebral artery during the acute stage. J Neurosurg 99 : 960-966, 2003

8. Kashiwazaki D, Ushikoshi S, Asano T, Kuroda S, Houkin K : Long-term clinical and radiological results of endovascular internal trapping in vertebral artery dissection. Neuroradiology $55: 201-206,2013$

9. Kim BC, Kwon OK, Oh CW, Bang JS, Hwang G, Jin SC, et al. : Endovascular internal carotid artery trapping for ruptured blood blister-like aneurysms : long-term results from a single centre. Neuroradiology 56 : 211-217, 2014

10. Kim BM, Shin YS, Kim SH, Suh SH, Ihn YK, Kim DI, et al. : Incidence and risk factors of recurrence after endovascular treatment of intracranial vertebrobasilar dissecting aneurysms. Stroke 42 : 2425-2430, 2011

11. Kitanaka C, Sasaki T, Eguchi T, Teraoka A, Nakane M, Hoya K : Intracranial vertebral artery dissections : clinical, radiological features, and surgical considerations. Neurosurgery 34 : 620-626; discussion 626-627, 1994

12. Kocaeli H, Chaalala C, Andaluz N, Zuccarello M : Spontaneous intradural vertebral artery dissection : a single-center experience and review of the literature. Skull Base 19:209-218, 2009

13. Kurata A, Ohmomo T, Miyasaka Y, Fujii K, Kan S, Kitahara T : Coil embolization for the treatment of ruptured dissecting vertebral aneurysms. AJNR Am J Neuroradiol 22 : 11-18, 2001

14. Lee BH, Kim BM, Park MS, Park SI, Chung EC, Suh SH, et al. : Reconstructive endovascular treatment of ruptured blood blister-like aneurysms of the internal carotid artery. J Neurosurg 110 : 431-436, 2009

15. Meckel S, Singh TP, Undrén P, Ramgren B, Nilsson OG, Phatouros C, et al. : Endovascular treatment using predominantly stent-assisted coil embolization and antiplatelet and anticoagulation management of ruptured blood blister-like aneurysms. AJNR Am J Neuroradiol 32 : 764771, 2011
16. Meling TR, Sorteberg A, Bakke SJ, Slettebø H, Hernesniemi J, Sorteberg W : Blood blister-like aneurysms of the internal carotid artery trunk causing subarachnoid hemorrhage : treatment and outcome. J Neurosurg 108 : 662-671, 2008

17. Mizutani T : Subarachnoid hemorrhage associated with angiographic "stenotic" or "occlusive" lesions in the carotid circulation. Surg Neurol 49: 495-503; discussion 503-504, 1998

18. Mizutani T, Aruga T, Kirino T, Miki Y, Saito I, Tsuchida T : Recurrent subarachnoid hemorrhage from untreated ruptured vertebrobasilar dissecting aneurysms. Neurosurgery 36 : 905-911; discussion 912-913, 1995

19. Mohammadian R, Taheraghdam AA, Sharifipour E, Mansourizadeh R, Pashapour A, Shimia M, et al. : Endovascular treatment of intracranial artery dissection : clinical and angiographic follow-up. Neurol Res Int $2013: 968380,2013$

20. Nakatomi H, Nagata K, Kawamoto S, Shiokawa Y : Ruptured dissecting aneurysm as a cause of subarachnoid hemorrhage of unverified etiology. Stroke 28 : 1278-1282, 1997

21. Ohkuma H, Nakano T, Manabe H, Suzuki S : Subarachnoid hemorrhage caused by a dissecting aneurysm of the internal carotid artery. J Neurosurg $97: 576-583,2002$

22. Rabinov JD, Hellinger FR, Morris PP, Ogilvy CS, Putman CM : Endovascular management of vertebrobasilar dissecting aneurysms. AJNR Am J Neuroradiol 24 : 1421-1428, 2003

23. Sakata N, Takebayashi S, Kojima M, Masawa N, Suzuki K, Takatama M : Pathology of a dissecting intracranial aneurysm. Neuropathology 20 : 104-108, 2000

24. Sim SY, Chung J, Shin YS : Are blood blister-like aneurysms a specific type of dissection? A comparative study of blood blister-like aneurysms and ruptured mizutani type 4 vertebral artery dissections. J Korean Neurosurg Soc 56 : 395-399, 2014

25. Sugiu K, Tokunaga K, Watanabe K, Sasahara W, Ono S, Tamiya T, et al. : Emergent endovascular treatment of ruptured vertebral artery dissecting aneurysms. Neuroradiology 47 : 158-164, 2005

26. Taha MM, Sakaida H, Asakura F, Maeda M, Toma N, Yamamoto A, et al. : Endovascular management of vertebral artery dissecting aneurysms : review of 25 patients. Turk Neurosurg $20: 126-135,2010$

27. Takemoto K, Abe H, Uda K, Inoue T : Surgical treatment of intracranial VA dissecting aneurysm. Acta Neurochir Suppl $107: 51-56,2010$

28. Uhl E, Schmid-Elsaesser R, Steiger HJ : Ruptured intracranial dissecting aneurysms : management considerations with a focus on surgical and endovascular techniques to preserve arterial continuity. Acta Neurochir (Wien) 145 : 1073-1083; discussion 1083-1084, 2003

29. van Oel LI, van Rooij WJ, Sluzewski M, Beute GN, Lohle PN, Peluso JP : Reconstructive endovascular treatment of fusiform and dissecting basilar trunk aneurysms with flow diverters, stents, and coils. AJNR Am J Neuroradiol 34 : 589-595, 2013

30. Yamada M, Kitahara T, Kurata A, Fujii K, Miyasaka Y : Intracranial vertebral artery dissection with subarachnoid hemorrhage : clinical characteristics and outcomes in conservatively treated patients. J Neurosurg $101: 25-30,2004$

31. Yamaura A, Watanabe Y, Saeki N : Dissecting aneurysms of the intracranial vertebral artery. J Neurosurg 72 : 183-188, 1990

32. Yonekawa Y, Zumofen D, Imhof HG, Roth P, Khan N : Hemorrhagic cerebral dissecting aneurysms : surgical treatments and results. Acta Neurochir Suppl $103: 61-69,2008$ 